\title{
Tumor de Buschke-Lowestein: Tratamento com Imiquimod para Preservação Esfincteriana. Relato de Caso
}

\author{
Buschke-Lowenstein Tumor: Imiquimod Therapy to \\ Esphincter Preservation. Case Report
}

\author{
FERNANDA MEIRAPINTO COELHO ${ }^{1}$; ALINE LANDIM MANO²; MELINADA SILVABACELLAR ${ }^{3}$; LINAMARIA GÓES \\ DECODES $^{4}$; ELIAS LUCIANO QUINTO DE SOUZA ${ }^{5}$; EULER DE MEDEIROS AZARO FILHO ${ }^{6}$
}

\begin{abstract}
${ }^{1}$ Médica estagiária de Coloproctologia do Hospital São Rafael; ${ }^{2}$ Médica residente de Coloproctologia do Hospital São Rafael; ${ }^{3}$ Médica assistente de Coloproctologia do Hospital São Rafael; ${ }^{4}$ Médica assistente de Coloproctologia do Hospital São Rafael; ${ }^{5}$ Médico assistente de Coloproctologia do Hospital São Rafael;

${ }^{6}$ Médico cordenador de Coloproctologia do Hospital São Rafael.
\end{abstract}

\begin{abstract}
COELHO FMP; MANO AL; BACELlAR MS; CODES LMG; SOUZA ELQ; AZARO FILHO EM. Tumor de Buschke-Lowestein: Tratamento com Imiquimod para Preservação Esfincteriana. Relato de Caso. Rev bras Coloproct, 2008;28(3): 342-346.

RESUMO: O tumor de Buschke-Lowestein, também conhecido como condiloma acuminado gigante é uma lesão de aspecto verrucoso, extensa, envolvendo a região ano-genital. Não representa uma lesão maligna por critérios histológicos, embora exista claramente um potencial de malignização, e tenha um comportamento agressivo. Não existe um consenso sobre o seu tratamento, aventando-se o uso de drogas quimioterápicas aplicadas local ou sistematicamente, uso de imunoterapia, radioterapia e ressecções cirúrgicas amplas isoladas ou em combinação com outras terapias. Relatamos um caso onde a opção de tratamento foi o imiquimod creme 5\%. A lesão envolvia musculatura esfincteriana e, sendo assim, a cirurgia acarretaria perda da continência fecal, causando ao paciente o ônus de um estoma definitivo. Após tratamento durante 20 semanas, o tumor apresentou regressão significativa de tamanho, sendo realizado excisão local da lesão residual com preservação esfincteriana.
\end{abstract}

Descritores: Condiloma acuminado; Imiquimod; tumor de Buschke-Lowenstein; HPV; tratamento.

\section{INTRODUÇÃO}

O condiloma acuminado gigante ou tumor de Buschke-Lowenstein (TBL) é uma forma rara de apresentação do condiloma acuminado anogenital, que por sua vez é uma doença sexualmente transmissível relacionada ao Papilomavírus humano (HPV) ${ }^{(1)}$.

A descrição clássica do TBL é uma grande lesão vegetante, verrucosa, de aspecto exofítico. Possui um crescimento lento e a despeito das suas características histopatológicas demonstrarem tratar-se de um tumor benigno, tem um comportamento agressivo localmente ${ }^{(2)}$. Estas lesões podem ser consideradas também como lesões de risco para transformação e desenvolvimento de carcinoma escamo-celular. ${ }^{(3)}$
A melhor estratégia terapêutica no TBL não foi estabelecida. Têm sido usado agentes tópicos, imunoterapia, quimiorradioterapia e cirurgia. A cirurgia, isoladamente ou em conjunto com outros métodos, pode ocasionar ressecções extensas e a invasão do esfíncter anal pode levar a uma ressecção abdominoperineal. ${ }^{(4)}$

Outra característica muito frequiente do TBLé a sua tendência em recidivar, com índices de recorrência em torno de $60 \%$. $^{(5)}$

O imiquimod é uma substância imunomoduladora que vem sendo usada no tratamento de lesões virais, capaz de potencializar a resposta imunológica ao HPV.(6) Por causa da extensão da doença deste paciente, optamos por iniciar o tratamento com imiquimod, e em de- 
corrência da excelente resposta obtida, apresentamos a opção de incluir esta terapia no tratamento do TBL.

\section{RELATO DE CASO}

Paciente do sexo masculino, 40 anos, homossexual, com sorologia positiva para o vírus da imunodeficiência humana há 11 anos. Encontrava-se em tratamento regular com anti retrovirais com as drogas TMC 114, TMC 125, Ritonavir, Vireaid, Lamivudine há 01 ano e Fusion há 02 anos, apresentando contagem de células CD4 variando entre 380 a 500. Há 11 meses refere inicio do quadro clínico com queixa de dor anal e lesão vegetante de tamanho pequeno em região perianal, fez uso de analgésicos e antiinflamatórios tópicos, sem resposta clínica. Esta lesão apresentou aumento progressivo de tamanho nos últimos 02 meses, quando o paciente procurou ambulatório de coloproctologia do nosso serviço.

O exame proctológico identificou uma lesão vegetante, com aspecto verrucoso, com cerca de 15 centímetros de diâmetro, localizada em região perianal, ocupando principalmente quadrante anterior direito, com prolapso mucoso circunferencial associado. Ao toque retal verifica-se hipotonia esfincteriana. (Figura 1)

$\mathrm{Na}$ investigação diagnóstica do paciente, foi realizado ultra-som endoanal com aparelho bidimensional. Este exame evidenciou imagem hiperecogênica envolvendo o esfíncter interno do ânus e ultrapassando seus limites, com acometimento da musculatura estriada (esfíncter externo do ânus), principalmente ao nível do canal anal inferior.

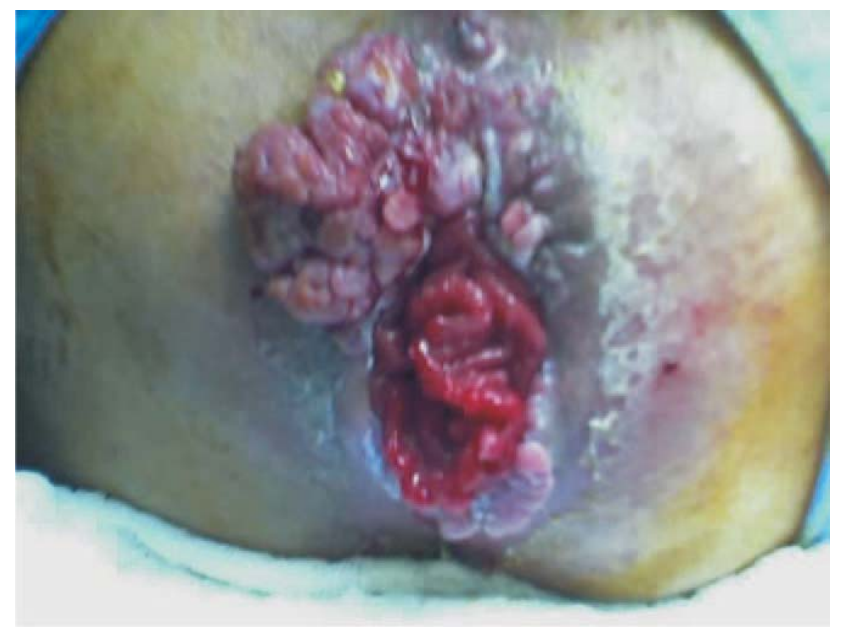

Figura 1 - Lesão vegetante e verrucosa em região perianal prévia ao tratamento.
Foi realizado biópsia da lesão sob narcose, que evidenciou Condiloma acuminado com displasia moderada e alterações compatíveis com ação viral.

Realizado tratamento imunoterápico com imiquimod creme 5\%, uso tópico, três vezes por semana durante 20 semanas, com seguimento mensal. A lesão apresentou regressão significativa de tamanho, persistindo em região posterior (Figura 2). Novo exame ultra-sonográfico verificou acometimento residual de musculatura de esfíncter externo e prolapso mucoso associado (Figuras 3 e 4 ).

O paciente referiu alteração da continência fecal precocemente. No $15^{\circ}$ dia pós-operatório, retornou já referindo melhora da incontinência. Ao exame físico, apresentava ferida operatória com parte da musculatura externa recoberta de tecido de granulação.

O paciente encontra-se em acompanhamento trimestral. No $10^{\circ}$ mês, não há recidiva da lesão (Figura 6). Optou-se por ressecção total da lesão que de fato não envolvia esfíncter interno, e ressecção parcial de mucosa prolapsada por apresentar escarificação em sua superfície (Figura 5).

\section{DISCUSSÃO}

O condiloma acuminado da região anogenital é causado pelo Papilomavírus humano (HPV), e os tipos $6,11,16$ e 18 são os principais responsáveis. ${ }^{(7)}$ Foi considerada a doença sexualmente transmissível mais diagnosticada em nosso meio. Sua incidência vem aumentando, associada a estados de imunossupressão, particularmente à AIDS. ${ }^{(8)}$ Nestes pacientes, costuma

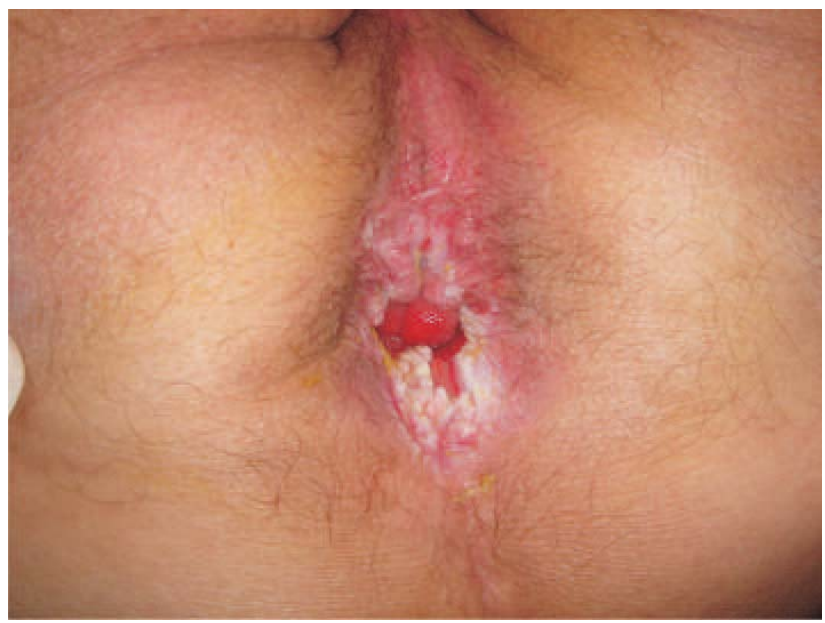

Figura 2 - Lesão residual após tratamento com Imiquimod. 


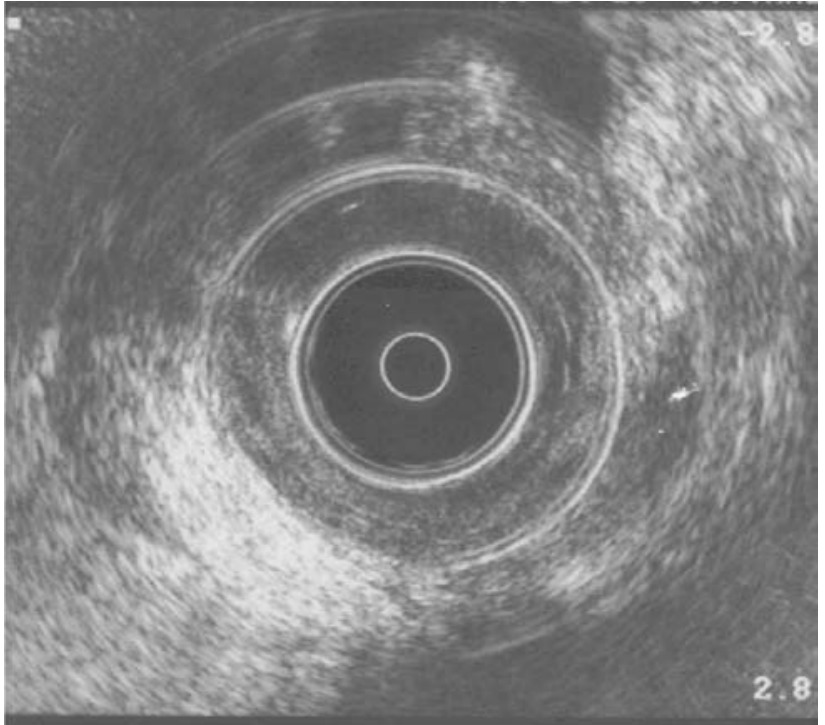

Figura 3 - Aspecto ultra-sonográfico da lesão acometendo musculatura estriada.

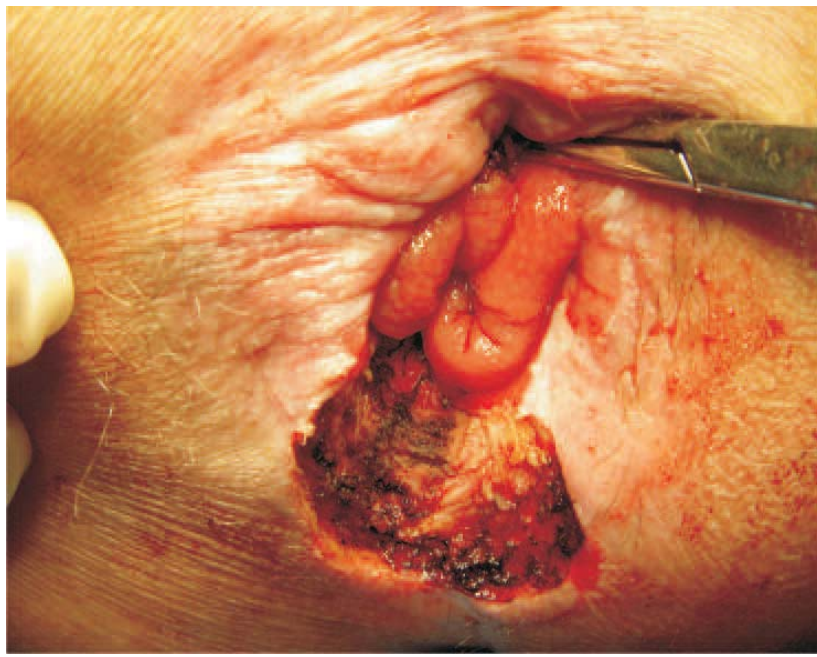

Figura 5 - Pós-ressecção da lesão.

ser mais agressivo, com crescimento rápido, alto índice de recidiva e pouca resposta à terapia convencional. ${ }^{(9)}$

O Tumor de Buschke-Lowestein ou condiloma acuminado gigante é a forma de apresentação onde à lesão atinge proporções muito volumosas, com características locais de agressividade, invadindo e causando deformidade nos tecidos adjacentes. Pode apresentar fistulização, porém não ocorre invasão linfática, vascular ou neuronal, além de não possuir potencial de metastatização. ${ }^{(10)} \mathrm{O}$ risco de degeneração do TBL para carcinoma escamo-celular é alto, variando entre

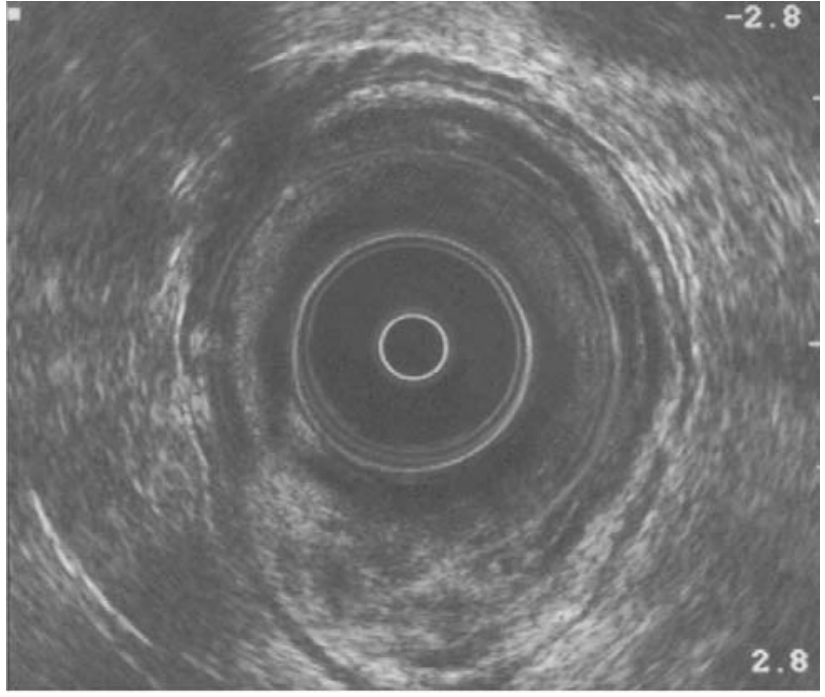

Figura 4 - Aspecto ultra-sonográfico do prolapso mucoso.

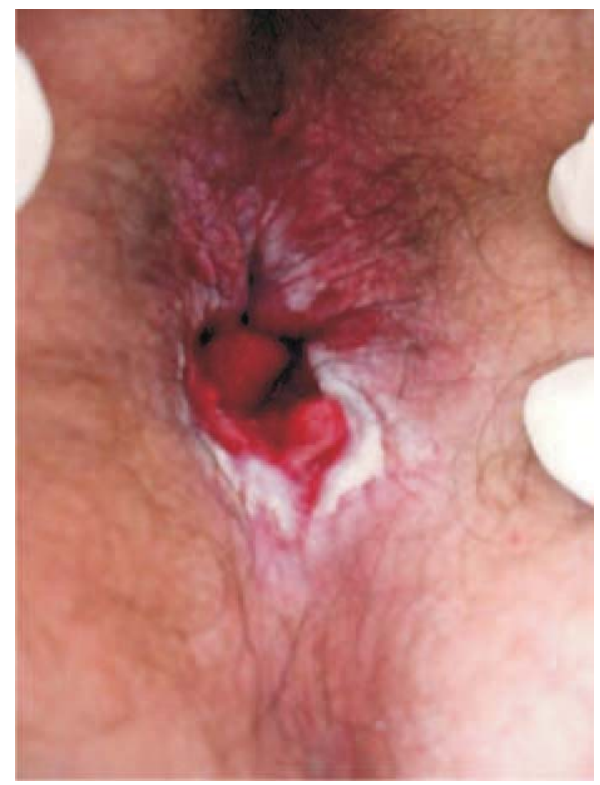

Figura 6 - Resultado final.

30 a $56 \%$, diferindo do condiloma acuminado simples, que possui uma incidência de apenas $2 \%$. $^{(11,12)}$

Existem diversas abordagens terapêuticas para o condiloma acuminado gigante, com medicações tópicas, criocirurgia, excisão cirúrgica, imunoterapia, quimioterapia, radioterapia, laser, eletrocoagulação e oxigenoterapia hiperbárica. ${ }^{(13,14)}$

No TBL, devido à sua extensão, ao índice alto de recorrência e pelo risco de malignização, a excisão radical é o tratamento mais utilizado, isoladamente ou em combinação com outras modalidades terapêuticas. ${ }^{(15)}$ 
Rev bras Coloproct Julho/Setembro, 2008
Tumor de Buschke-Lowestein: Tratamento com Imiquimod

para Preservação Esfincteriana. Relato de Caso

Fernanda Meira Pinto Coelho e Cols.
Vol. 28 $\mathbf{N}^{\circ} 3$
Nós relatamos um caso de TBL com envolvimento significativo da musculatura interna e externa do ânus. Este padrão de acometimento acarretaria uma opção cirúrgica com excisão ampliada ou uma amputação abdominoperineal, o que levaria ao paciente o ônus de incontinência ou até mesmo de um estoma definitivo. Devido a este fato, optamos por tentar uma modalidade terapêutica com o uso de uma substância imunomoduladora, o Imiquimod creme a 5\%.

O Imiquimod é uma medicação tópica imunoterápica da família imidazoquinolina, atua pela indução da produção de interferon alfa e citocinas, potencializando a resposta imunológica contra as células infectadas pelo HPV. $(16,17)$

Imiquimod creme a 5\% é aplicado topicamente pelo próprio paciente. Este tratamento já é reconhecido como uma opção para lesões anogenitais causadas pelo HPV, e tem sido usado com êxito no tratamento de lesões pré-malignas e malignas da pele como Doença de Bowen e ceratose actínica. ${ }^{(18)}$
Os efeitos colaterais são mínimos e não exigem interrupção do tratamento, sendo relatados queimação local, eritema e ulcerações cutâneas superficiais. ${ }^{(6,18)}$ Um fator limitante do uso mais amplo, em nosso meio, é que se trata de uma medicação dispendiosa.

É preconizado o uso do Imiquimod creme a $5 \%$, três vezes por semana, em dias alternados, por um período de 12 a 16 semanas. Nosso plano terapêutico seguiu esta recomendação, porém estendemos para 20 semanas devido à permanência de lesões residuais. Após este período não houve regressão total, permanecendo pequena área afetada, que foi tratada com excisão local. Durante o tratamento, observou-se substituição das verrugas por tecido cicatricial e esbranquiçado.

Após 10 meses de tratamento, o paciente encontra-se livre de doença, e mantém acompanhamento trimestral. Este seguimento é necessário para vigilância de lesões malignas, devido ao TBL possuir alto índice de recidiva. ${ }^{(19)}$

\footnotetext{
ABSTRACT: Buschke-Lowestein tumor or giant condyloma acuminatum is a verrucous, large lesion in the anorectal and perianal regions. It is not a malignant lesion in histopathologic findings. However, there is a risk of malignancy and trends an aggressive behavior. There is not a gold standard therapy, with the use of topical or systemic chemotherapy, immunotherapy, radiation therapy and large surgical resections. These surgical resections can be doing alone or in combinations with others therapies (multimodality therapy). The authors describe a case that the treatment option was the imiquimod cream 5\%. The lesion invades in the anal sphincters, so fecal incontinence will result after surgery and a colostomy was mandatory. After 20 weeks treatment, the tumor presented a great regression, and it was treated with local excision and avoided a mutilating procedure.
}

Key words: Condyloma acuminatum; Imiquimod; Buschke-Lowenstein tumor; HPV; Treatment.

\section{REFERÊNCIAS}

1. Miles AJG, Mellor CH, Gazzard B, Allen-Mersh TG, Wastell C. Surgical management of anorectal disease in HIV- positive homosexuals. Br J Surg, 1990;77:869-71.

2. Trombetta LJ, Place RJ. Giant condyloma acuminatum of the anorectum: trends in epidemiology and management: report of a case and review of the literature. Dis colon Rectum 2001; 44(12): 1878-86.

3. Chao MW, Gibbs P. Squamous cell carcinoma arising in giant condyloma acuminatum (Buschke-Lowestein tumor). Asian J Surg. 2005 Jul; 28(3):238-40.

4. Bertram P, Treutner KH, Rubben A, Hauptmann S, Schumpelick V. Invasive squamous-cell carcinoma in giant anorectal condyloma (Buschke-Lowestein tumor). Langenbecks Arch Chir. 1995;380(2):115-8.
5. Mistrangelo M, Mobiglia A, Cassoni P, Castellano I, Maass J, Martina MC et al. Verrucous carcinoma of the anus or BuschkeLowestein tumor of the anus: staging and treatment. Report of 3 cases. Suppl Tumori. 2005 May-jun;4(3):S29-30.

6. Lopes-Paulo F. O uso do imiquimod no tratamento de lesões anais induzidas por HPV. Rev bras Coloproct, 2005;25(3): 269-271.

7. Sobrado CW, Andraus W, Marques CFS, Nahas SC, Bochini $\mathrm{SF}$, Nadalin $\mathrm{V}$ et al. Condiloma acuminado perianal gigante recidivante tratado com radioterapia. Experiência inicial e relato de caso. Ver bras Coloproct, 1999; 19(2): 103-107.

8. Palefsky J, Holly EA, Gonzales J, Lamborn K, Hollander H. Natural history of anal cytologic abnormalities and papillomavirus infection among homosexual men with group IV HIV disease. J AIDS, 1992; 5: 1258-65

9. Safavi A, Gottesman L, Dailey TH. Anorectal surgery in the HIV patient: update. Dis Colon Rectum, 1991; 34: 299-304. 
10. Hull MT, Eble JN, Priest JB, Mulcahy JJ. Ultraestructure of Buschke-Lowenstein tumor. J urol 1981; 126(4): 485-89.

11. Hyacinthe M, Karl R, Coppola D, Goodgame T, Redwood W, Goldenfarb P et al. Squamous-Cell Carcinoma of the Pelvis in a Giant Condyloma Acuminatum: Use of neoadjuvant chemoradiation and surgical resection. Report of a case. Dis Colon Rectum 1998; 41: 1450-1453.

12. Prasad ML, Abcarian H. Malignant potential of perianal condyloma acuminatum. Dis Colon Rectum 1980; 23: 191-7.

13. Tytherleigh MG, Birtle AJ, Cohen CE, Livingstone J, Gilbert J. Combined surgery and chemoradiation as a treatment for the Buschke-Lowenstein tumour. The Surgeon, 2006; 4(6): 368-383.

14. Fox PA. Human papillomavirus and anal intraepithelial neoplasia. Curr Opin Infect Dis, 2006; 19(1): 62-6

15. Levy A, Lebbe C. Busckhe-Lowenstein tumour: diagnosis and treatment. Ann Urol (Paris), 2006; 40(3):175-8.

16. Nadal SR, Manzione CR, Horta SHC, Calore EE. Sistematização do atendimento dos portadores de infecção perianal pelo papilomavirus humano (HPV). Rev bras Coloproct, 2004; 24(4):322-328

17. Pehoushek J, Smith KJ. Imiquimod and 5\% Fluorouracil Therapy for Anal and Perianal Squamous Cell Carcinoma in situ in an HIV-1 positive man. Arch Dermatol, 2001; 137: 14-16.

18. Kaspari M, Gutzmer R, Kaspari T, Kapp A, Brodersen JP. Br J Dermatol 2002; 147: 757-759.

19. Chu QD, Vezeridis MP, Libbey NP, Wanebo HJ. Giant condyloma acuminatum (Busckhe-Lowenstein tumor) of the anorectal and perianal regions. Analysis of 42 cases.

\section{Endereço para correspondência:}

FERNANDA MEIRA PINTO COELHO

Endereço Rua dos Radialistas 181/806, Pituba, Salvador-BA, CEP 41.810-650

Tel: 71- 21096369 / 71- 99828316

Fax: 71- 33506202

E-mail:drafernandacoelho@bol.com.br 